\title{
EFFECT OF MOLECULAR WEIGHT, BRANCHING AND TEMPERATURE ON DYNAMICS OF POLYPROPYLENE MELTS AT VERY HIGH SHEAR RATES
}

\author{
Jiri Drabek $^{1}$, Martin Zatloukal ${ }^{1, *}$ and Mike Martyn ${ }^{2}$ \\ ${ }^{1}$ Polymer Centre, Faculty of Technology, Tomas Bata University in Zlín, \\ Vavrečkova 275, 76001 Zlín, Czech Republic \\ ${ }^{2}$ IRC in Polymer Engineering, School of Engineering, Design \& Technology, \\ University of Bradford, Bradford BD7 1DP, UK
}

Keywords: High shear rate rheology, secondary Newtonian viscosity, polymer melt, branching.

*Corresponding author: mzatloukal@utb.cz 


\section{ABSTRACT}

Dynamics of linear polypropylene (L-PP) and long-chain branched polypropylene (LCB-PP) miscible blends, having weight average molecular weight between $64-78 \mathrm{~kg} / \mathrm{mol}$, was investigated via high shear rate rheology. Results obtained were compared with the corresponding data for L-PP. Highshear rate secondary Newtonian plateaus, $\eta_{\infty}$, were identified at three different temperatures for well entangled L-PP/LCB-PP blends above shear rates of $2 \cdot 10^{6} 1 / \mathrm{s}$ and their dependence on weight average molecular weight, $M_{w}$, was successfully related as $\eta_{\infty}(T)=K_{\infty}(T) \cdot M_{w}{ }^{n}$ with the exponent $\mathrm{n}=1.010$. Interestingly, the temperature dependant proportionality constant $K_{\infty}$ was found to be about $10-20 \%$ lower for the blend in comparison with the pure L-PP whereas the parameter $n$ was found to be the same for both systems. The average values of high-shear rate flow activation energy, $E_{\infty}$, for the blends was found to be slightly lower than for pure L-PP and comparable with low-shear rate flow activation energy of PP like oligomer squalane $\left(\mathrm{C}_{30} \mathrm{H}_{62} ; 2,6,10,15,19,23\right.$-hexamethyltetracosane). This suggests that polymer chains are fully disentangled at very high shear rates and chain branching can enhance the flow in this regime due to smaller coil size and higher availability of the free volume (i.e. lower monomeric friction coefficient) in comparison with their linear counterparts. 
Knowledge of polymer melt dynamics at very high shear rates is essential for the optimization and development of new materials utilized for the fabrication of nano-products via advanced technologies such as 3D printing, micromolding, nano-imprint lithography, melt electrospinning or melt blowing. Polymer melts in these processes are typically exposed to very high shear rates $\left(10^{6}-10^{7} 1 / \mathrm{s}\right)$ [1-5]. There are only a few papers reporting shear viscosity measurements for polymer melts at such extreme shear rates utilizing specially designed rheological equipment such as hydraulically powered capillary rheometers [6] or instrumented injection molding machines [7-11]. Recent studies on entangled linear polypropylene melts have shown a well-developed Newtonian regime occurs above $2 \cdot 10^{6} 1 / \mathrm{s}$, which is linearly dependant on molecular weight suggesting that polymer chains become fully disentangled in such a flow regime [11]. In order to understand the role of the chain branching and temperature on high shear rate dynamics of polypropylene melts, well characterized low molecular weight linear PP Borflow HL512FB (L-PP) [11] and high molecular weight branched PP Daploy WB180HMS (LCB-PP) [12], both produced by Borealis Polyolefine (Linz, Austria), have been used in this work. Polymer blends were prepared by adding 10, 20 and 30 wt\% of LCB-PP to L-PP in a twin screw extruder. These systems are miscible for blends containing up to $50 \mathrm{wt} \%$ LCB-PP [13-17]. High shear rate rheology was conducted at 190,210 and $230^{\circ} \mathrm{C}$ on a high accuracy Fanuc Roboshot S-2000i electric high-speed injection molding machine in air-shot mode using an instrumented rheometric capillary die nozzle under processing conditions, in which the effect of viscous dissipation and pressure is mutually cancelled [11]. A capillary die of $8 \mathrm{~mm}$ length and diameter $0.5 \mathrm{~mm}$ as well as an orifice die of the same diameter were used to enable Bagley and Weissenberg-Rabinowitsch corrections. More details about this instrument and its accuracy are provided in [7, 11]. Molecular weight distributions and basic molecular weight averages were determined from high temperature gel permeation chromatography of the PP extrudates rheologically evaluated (i.e. processed) at high shear rates (see Fig. 1 and Table 1). Zero-shear viscosities, $\eta_{0}$, of processed samples were measured on an Advanced Rheometric Expansion System (ARES 2000 model, Rheometrics Scientific, USA) in parallel plate mode 
at $190,200,210,220,230$ and $240^{\circ} \mathrm{C}$. Shear viscosity data measured at very high deformation rates $(1$. $10^{6}-7 \cdot 10^{6} 1 / \mathrm{s}$ ) are provided in Fig. 2 for all three L-PP/LCB-PP blends at $230^{\circ} \mathrm{C}$.

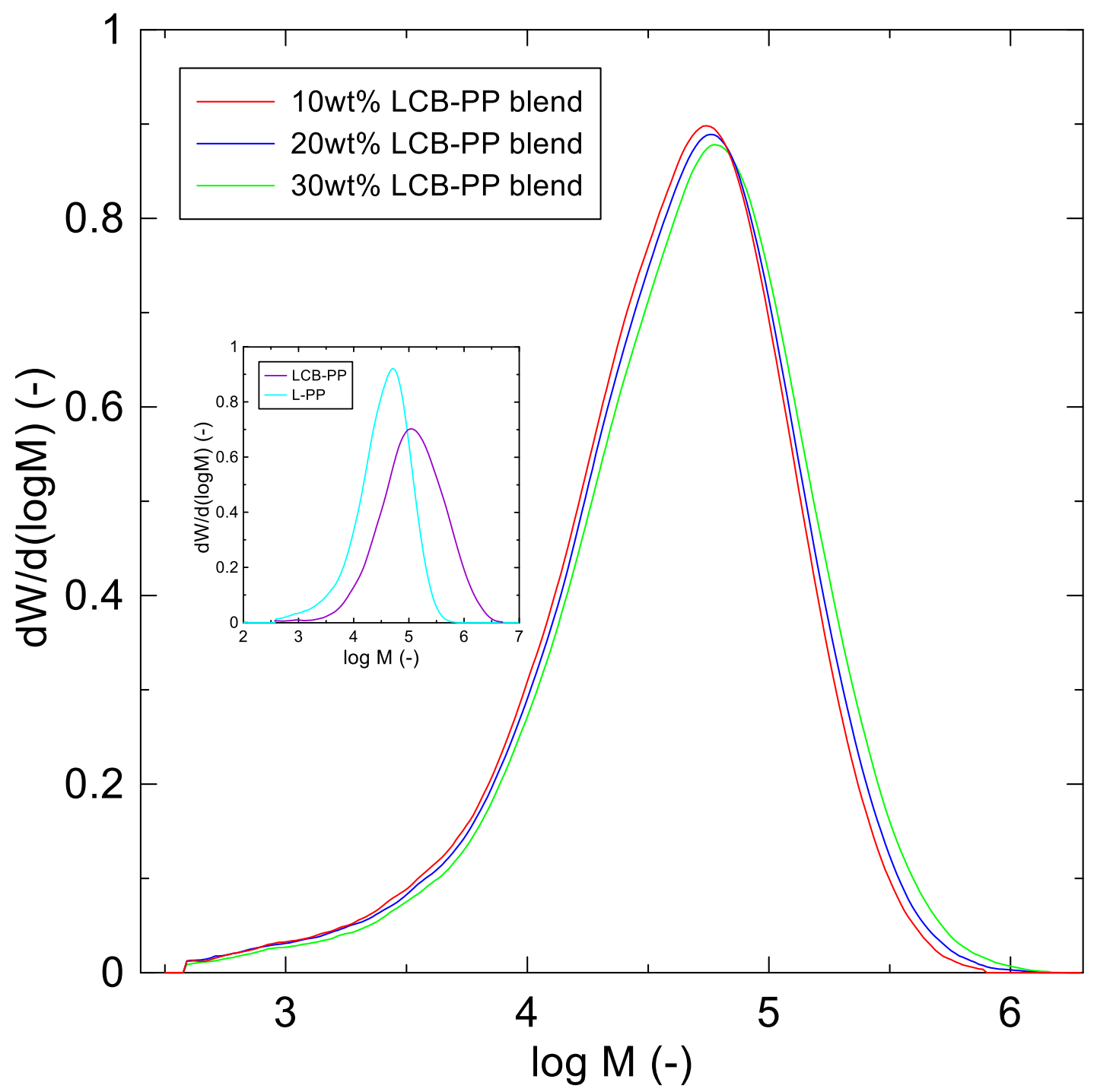

Figure 1 Molecular weight distribution (MWD) curves for 10wt \%, 20wt \% and 30wt $\%$ LCB-PP blends (processed samples, i.e. high shear rate extrudates).

Table 1. Molecular characteristics of processed polypropylene melts (i.e. high shear rate extrudates).

\begin{tabular}{|c|c|c|c|c|c|}
\hline $\begin{array}{c}\text { Sample } \\
\text { Name }\end{array}$ & $\begin{array}{c}\mathbf{M n} \\
\left(\mathbf{g . m o l}^{-1}\right)\end{array}$ & $\begin{array}{c}\mathbf{M}_{\mathbf{w}} \\
\left(\mathbf{g . m o l}^{-\mathbf{1}} \mathbf{)}\right.\end{array}$ & $\begin{array}{c}\mathbf{M}_{\mathbf{z}} \\
\left(\mathbf{g . m o l}^{-\mathbf{1}} \mathbf{)}\right.\end{array}$ & $\begin{array}{c}\mathbf{M}_{\mathbf{z + 1}} \\
(\mathbf{g . m o l} \mathbf{- 1})\end{array}$ & $\begin{array}{c}\mathbf{M}_{\mathbf{w}} \mathbf{/} \mathbf{M} \mathbf{n} \\
(-\mathbf{)}\end{array}$ \\
\hline HL508FB (64k) & 14650 & 63750 & 138000 & 235500 & 4.35 \\
\hline HL512FB (56k) & 14250 & 56250 & 114500 & 187500 & 3.95 \\
\hline Blend 1 & 15200 & 64100 & 139000 & 237000 & 4.22 \\
\hline Blend 2 & 15600 & 69700 & 161500 & 303500 & 4.47 \\
\hline Blend 3 & 17350 & 78150 & 191000 & 373500 & 4.50 \\
\hline Daploy & 36950 & 246500 & 815000 & 1705000 & 6.67 \\
\hline
\end{tabular}




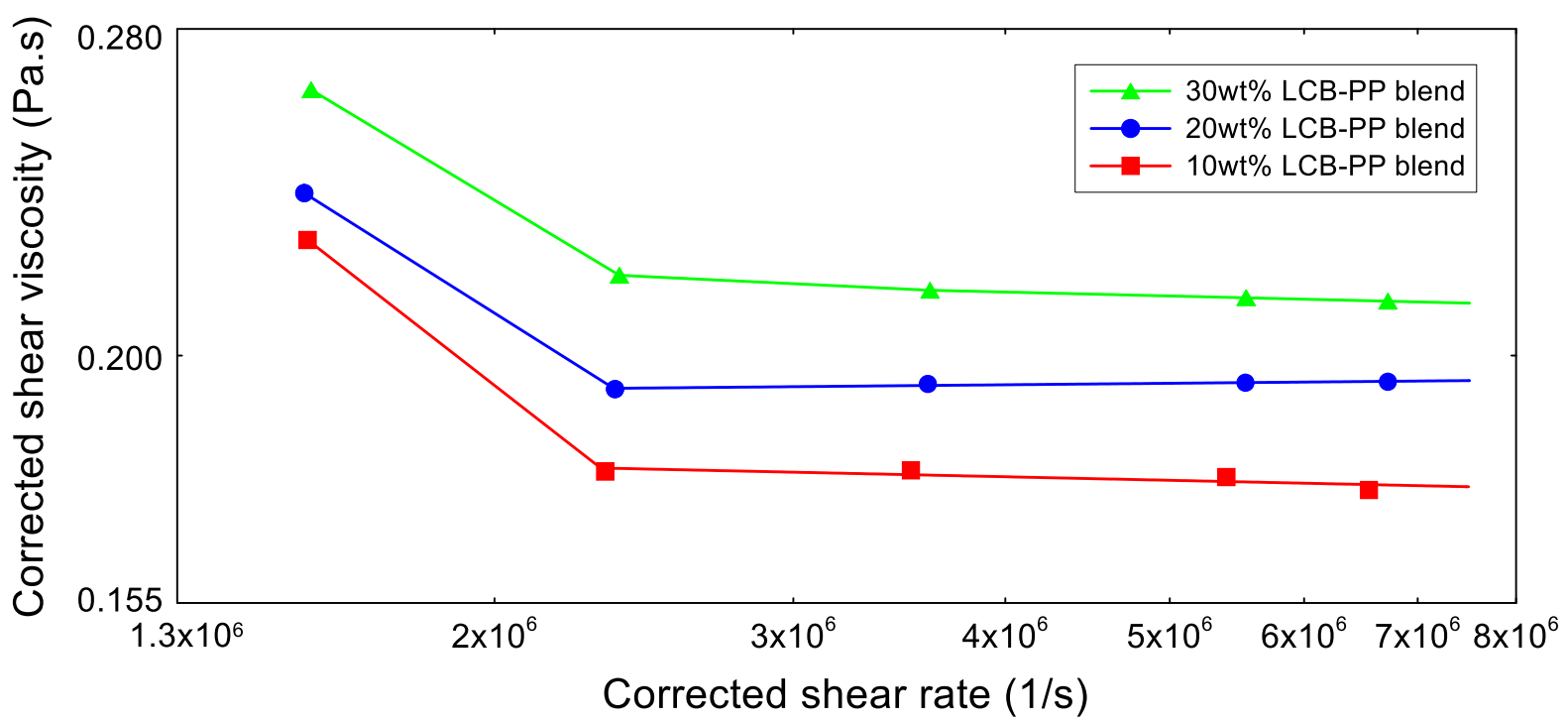

Figure 2 Deformation rate dependent shear viscosity data for given L-PP/LCB-PP blends at $230^{\circ} \mathrm{C}$. The term "Corrected" utilized here for shear viscosity and shear rate means that Bagley as well as Weissenberg-Rabinowitsch corrections were applied.

A well developed secondary Newtonian plateau viscosity, $\eta_{\infty}$, can easily be identified for all three samples between $2 \cdot 10^{6} 1 / \mathrm{s}$ and $7 \cdot 10^{6} 1 / \mathrm{s}$. Measured values of $\eta_{0}$ and $\eta_{\infty}$ at different temperatures, which are summarized in Table 2, were used to determine the flow activation energy of the L-PP/LCBPP blends at low $\left(E_{0}\right)$ and high $\left(E_{\infty}\right)$ shear rates using Arrhenius plots (see Figure 3$)$.

Table 2. Summary of experimentally determined values for zero shear viscosity, $\eta_{0}$, and secondary Newtonian viscosity, $\eta_{\infty}$, at 190 and $230^{\circ} \mathrm{C}$.

\begin{tabular}{|c|c|c|c|c|}
\hline $\begin{array}{c}\text { Sample } \\
\text { name }\end{array}$ & $\begin{array}{c}\eta_{0} \\
(\text { Pa.s) }\end{array}$ & $\begin{array}{c}\text { Standard deviation } \\
\text { for } \eta_{0} \text { (Pa.s) }\end{array}$ & $\begin{array}{c}\boldsymbol{\eta}_{\infty} \\
(\text { Pa.s })\end{array}$ & $\begin{array}{l}\text { Standard deviation } \\
\text { for } \eta_{\infty}(\text { Pa.s })\end{array}$ \\
\hline \multicolumn{5}{|c|}{$\mathrm{T}=190^{\circ} \mathrm{C}$} \\
\hline Blend 1 & 35.51 & 1.744 & 0.287 & 0.0045 \\
\hline Blend 2 & 51.61 & 1.660 & 0.313 & 0.0046 \\
\hline Blend 3 & 77.61 & 2.368 & 0.347 & 0.0221 \\
\hline Daploy & 9236.86 & 34.097 & - & - \\
\hline \multicolumn{5}{|c|}{$\mathrm{T}=210^{\circ} \mathrm{C}$} \\
\hline Blend 1 & 19.78 & 1.036 & 0.204 & 0.0118 \\
\hline Blend 2 & 27.18 & 0.628 & 0.231 & 0.0143 \\
\hline Blend 3 & 43.38 & 1.706 & 0.253 & 0.0062 \\
\hline Daploy & 4558.24 & 16.826 & - & - \\
\hline \multicolumn{5}{|c|}{$\mathrm{T}=230^{\circ} \mathrm{C}$} \\
\hline Blend 1 & 11.59 & 0.235 & 0.176 & 0.0016 \\
\hline Blend 2 & 16.25 & 0.439 & 0.195 & 0.0016 \\
\hline Blend 3 & 24.51 & 0.973 & 0.216 & 0.0024 \\
\hline Daploy & 2379.33 & 8.783 & - & - \\
\hline
\end{tabular}




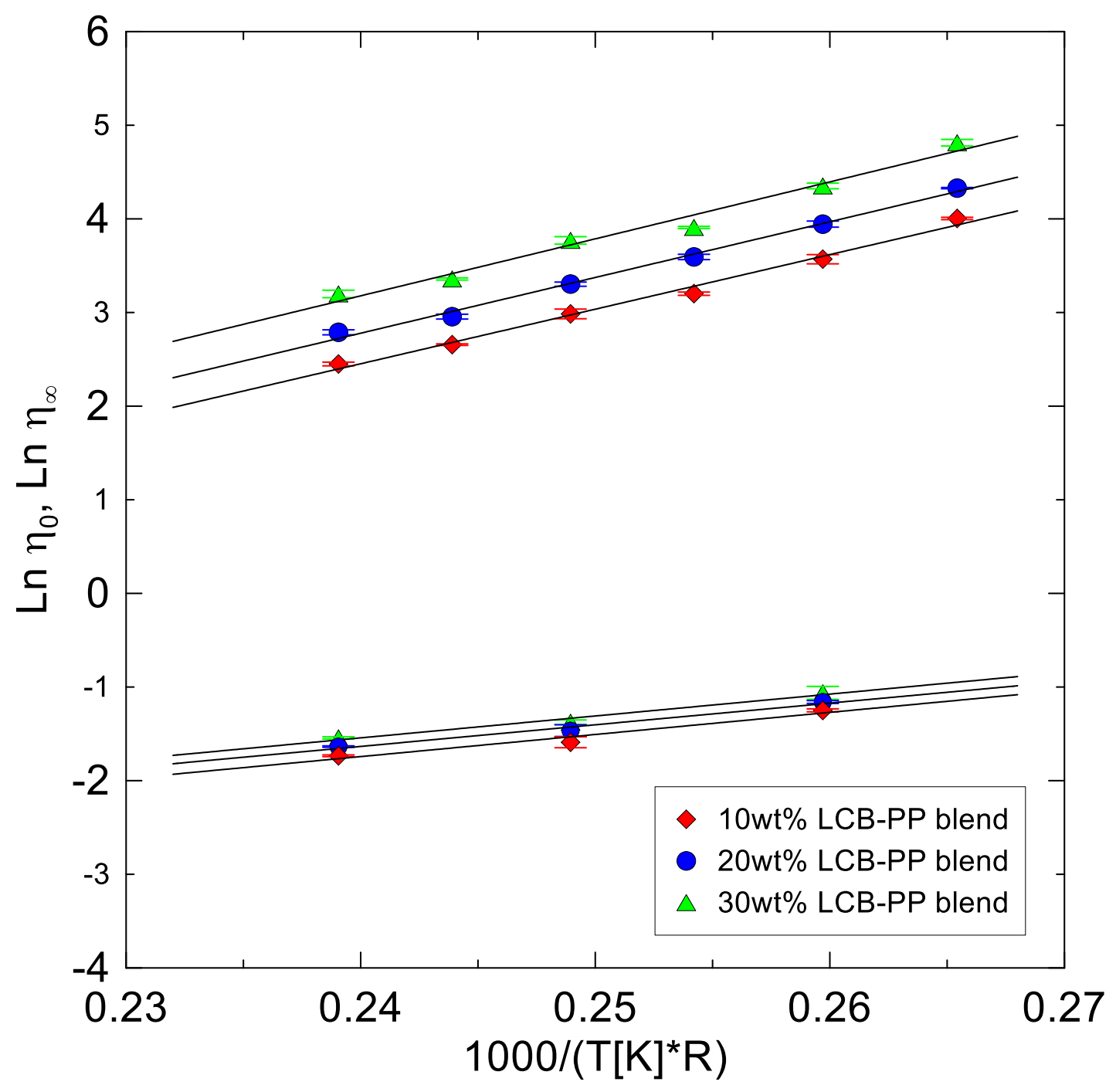

Figure 3 Arrhenius plot for 10wt $\%, 20 \mathrm{wt} \%$ and 30wt $\%$ LCB-PP blends utilizing $\eta_{0}$ (top) and $\eta_{\infty}$ (bottom).

$E_{0}$ was found to be $58.276 \mathrm{~kJ} / \mathrm{mol}$ for $10 \mathrm{wt} \%$ LCB-PP, $59.500 \mathrm{~kJ} / \mathrm{mol}$ for $20 \mathrm{wt} \% \mathrm{LCB}-\mathrm{PP}$ and 60.840 $\mathrm{kJ} / \mathrm{mol}$ for $30 \mathrm{wt} \%$ LCB-PP, i.e. slightly increasing with higher content of LCB-PP in the investigated polypropylene blends with an average value of $59.539 \pm 1.282 \mathrm{~kJ} / \mathrm{mol}$. As it is expected, these values lie between $E_{0}$ for pure L-PP $(56.558 \mathrm{~kJ} / \mathrm{mol}[11])$ and LCB-PP $(65.698 \mathrm{~kJ} / \mathrm{mol})$ samples. Obtained $E_{0}$ are in good correspondence with values reported in the literature for linear PPs $\left(\mathrm{E}_{0}=43-62 \mathrm{~kJ} / \mathrm{mol}[13\right.$, 18]), branched PPs $\left(\mathrm{E}_{0}=70-77 \mathrm{~kJ} / \mathrm{mol}[13,19]\right)$ and L-PP/LCB-PP blends $\left(43 \mathrm{~kJ} / \mathrm{mol}<\mathrm{E}_{0}<70 \mathrm{~kJ} / \mathrm{mol}\right.$ [13]). On the other hand, $E_{\infty}$, was found to be much smaller, $23.613 \mathrm{~kJ} / \mathrm{mol}$ for $10 \mathrm{wt} \% \mathrm{LCB}-\mathrm{PP}, 23.123$ $\mathrm{kJ} / \mathrm{mol}$ for $20 \mathrm{wt} \% \mathrm{LCB}-\mathrm{PP}$ and $23.366 \mathrm{~kJ} / \mathrm{mol}$ for $30 \mathrm{wt} \% \mathrm{LCB}-\mathrm{PP}$ (average value of $23.367 \pm 0.245$ $\mathrm{kJ} / \mathrm{mol}$ ). Relating average values of $E_{\infty}$ and $E_{0}$ yields the following relationship: 
$E_{\infty}=0.3925 \cdot E_{0}$

Interestingly, the $23.367 \mathrm{~kJ} / \mathrm{mol}$ average $E_{\infty}$ value for the blends is slightly lower than that of 25.204 $\mathrm{kJ} / \mathrm{mol} E_{\infty}$ for pure L-PP [11] and both values are comparable with $E_{0}$ for PP like oligomer squalane $(19.804 \pm 1.633 \mathrm{~kJ} / \mathrm{mol}[11,20])$ possessing no chain entanglements. The observed reduction in the flow activation energy can be explained through free volume increase at the secondary Newtonian plateau regime due to coalescence of shaped free volume cavities (as the result of complete chain disentanglement), which increases their size and makes the flow easier. Detailed discussion on the free volume concept, flow activation energy and polymer viscosity is provided in [21, 22]. The lower values of $E_{\infty}$ for the blends can be reasoned through a higher level of free volume availability at the secondary Newtonian region in comparison to that in L-PP.

$\eta_{0}$ and $\eta_{\infty}$ expressed as functions of average molecular weight in log-log scale were simultaneously fitted for all temperatures using the following simple power-law equations for the studied L-PP/LCB-PP polymer systems as well as for pure L-PP (utilizing data taken from Table 2 and Figure 6 provided in our recent publication [11]).

$\eta_{0}(T)=K_{0}(T) \cdot M_{w}{ }^{n}$

$\eta_{\infty}(T)=K_{\infty}(T) \cdot M_{w}{ }^{n}$

Comparison between the experimental data and the power-law model fits for the lowest $\left(190^{\circ} \mathrm{C}\right)$ and the highest $\left(230^{\circ} \mathrm{C}\right)$ applied temperatures is provided in Figure 4 . In the case of $\eta_{0}$, the power-law exponent for L-PP/LCB-PP blend $(n=4.049)$ is higher than for pure L-PP $(n=3.620)$. Additionally, the proportionality constant $K_{0}$, is smaller for blends at $190^{\circ} \mathrm{C}$ and $230^{\circ} \mathrm{C}$ being $1.25 \cdot 10^{-18}$, and 3.79 . $10^{-19}$ respectively compared to L-PP with a $K_{0}$ of $1.54 \cdot 10^{-16}$, and $4.81 \cdot 10^{-17}$ at the same temperatures. This increase in $K_{0}$ is caused by the higher number of chain entanglements due to presence of LCB-PP in the blend as to be expected. 

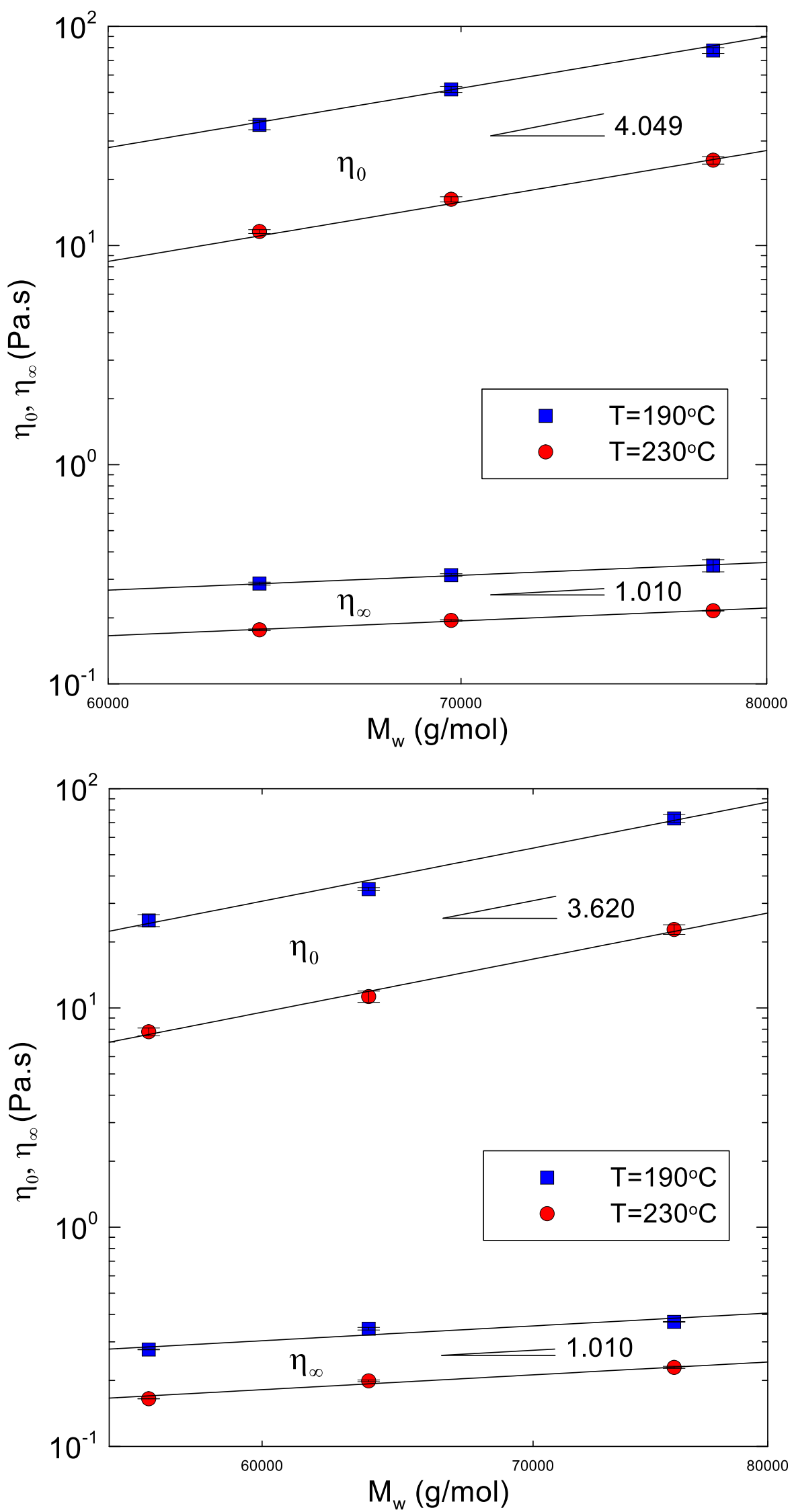

Figure 4 Effect of weight average molecular weight, $M_{w}$, and temperature on zero shear viscosity, $\eta_{0}$, and secondary Newtonian viscosity, $\eta_{\infty}$, for L-PP/LCB-PP blends (top) and L-PP (bottom). Note that L-PP data (i.e. for linear isotactic polypropylenes, namely HL504FB, HL508FB and HL512FB) were taken from Table 2 and Figure 6 provided in our recent publication [11]. 
In the case of $\eta_{\infty}$, the exponent $\mathrm{n}=1.010$ is the same for both systems whereas the proportionality constant $K_{\infty}$ is about $10-20 \%$ lower for the blend $\left(\mathrm{K}_{\infty}\left(\mathrm{T}=190^{\circ} \mathrm{C}\right)=4.00 \cdot 10^{-6}, \mathrm{~K}_{\infty}\left(\mathrm{T}=230^{\circ} \mathrm{C}\right)=2.48 \cdot 10^{-6}\right)$ in comparison with the pure L-PP $\left(\mathrm{K}_{\infty}\left(\mathrm{T}=190^{\circ} \mathrm{C}\right)=4.55 \cdot 10^{-6}, \quad \mathrm{~K}_{\infty}\left(\mathrm{T}=230^{\circ} \mathrm{C}\right)=2.72 \cdot 10^{-6}\right)$. The observed linear dependence between $\eta_{\infty}$ and molecular weight, as predicted by Rouse-Bueche molecular theory for polymer melts with no entanglements [23, 24], also supports the hypothesis that chains become fully disentangled in these polymer systems at very high shear rates. In such cases the proportionality constant $K_{\infty}$ should be given predominantly by the geometrical parameters characterizing the size/shape of the coil, such as for example mean square radius of gyration $\left\langle R^{2}\right\rangle$, and monomeric friction coefficient, $\zeta$. It was shown firstly that the coil dimensions of branched polymers are smaller than their linear counterparts [25] and secondly, $\zeta$ decreases with increased level of the free volume [21]. Thus, lower values of $K_{\infty}$ for L-PP/LCB-PP systems can be understood by the lower value of $\left\langle R^{2}\right\rangle$ and $\zeta$ in comparison with pure L-PP.

To clarify the role of the chain branching on the shear viscosity at high shear rates, $10 \mathrm{wt} \% \mathrm{LCB}-$ PP blend is compared with that of L-PP (type HL508FB, the experimental data are taken from our recent publication [11]), both having the same weight average molecular weight (64 kg/mol) and comparable polydispersity index (see Table 1). In such a case, the viscosity difference is given mainly by number of entanglements, size of the macromolecular coils and $\zeta$.

As seen in Figure 5 the blend has an expected higher shear viscosity compared to the linear PP due to dominantly higher number of entanglements up to a shear rate of $\sim 4500001 / \mathrm{s}$, but above this strain rate the trend is switched. The secondary Newtonian plateau, which starts to occur above a shear rate $2 \cdot 10^{6} 1 / \mathrm{s}$, is about $13 \%$ higher for linear PP $\left(\eta_{\infty}=0.199 \pm 0.0018\right.$ Pa.s [11] $)$ in comparison with the L-PP/LCB-PP blend ( $\eta_{\infty}=0.176 \pm 0.0016$ Pa.s $)$ at the $230^{\circ} \mathrm{C}$. In this entanglement free flow regime the observed difference in $\eta_{\infty}$ can primarily be attributed to smaller coils size and higher availability of the free volume (i.e. a smaller monomeric friction coefficient) for the blend in comparison with pure linear PP melt. 


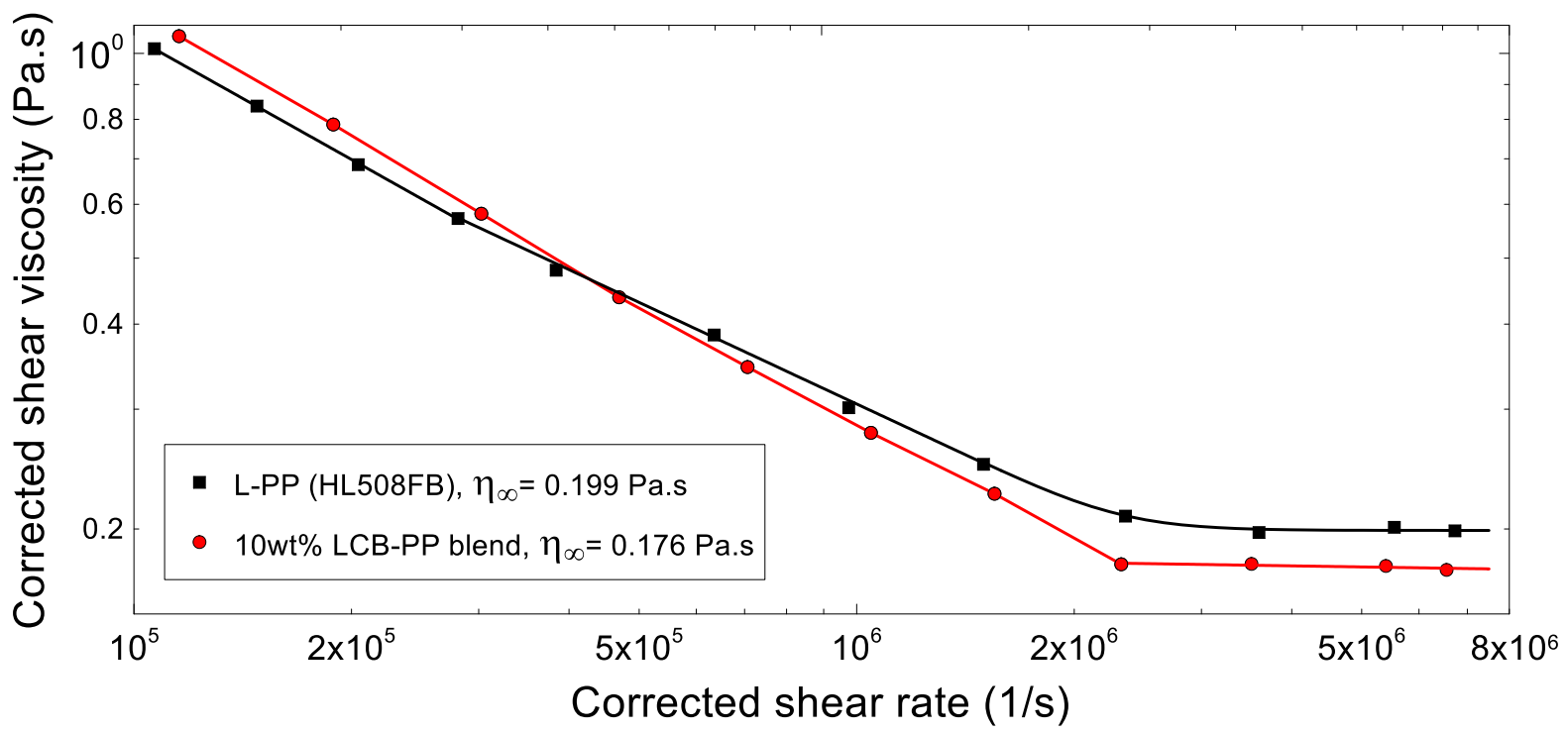

Figure 5 Deformation rate dependent shear viscosity for 10wt\% LCB-PP blend and L-PP (HL508FB [11]) having the same molecular weight $(64 \mathrm{~kg} / \mathrm{mol})$ and polydispersity index (about $4.3)$ at $230^{\circ} \mathrm{C}$. The term "Corrected" utilized here for shear viscosity and shear rate means that Bagley as well as Weissenberg-Rabinowitsch corrections were applied.

It is important to mention that, firstly, even if the variation of molecular parameters of the investigated samples is relatively small, reported $13 \%$ and $23 \%$ reduction in $\eta_{\infty}$ due to increased LCB and reduced $M_{w}$ (from 78 to $64 \mathrm{~kg} / \mathrm{mol}$ ), respectively, can be considered high enough to justify obtained structure-rheology relations. Secondly, only the samples with reasonably low molecular weight and elasticity can be used for stable high shear rate processing. For example, polymer samples with $M_{w}$ between 40 and $80 \mathrm{~kg} / \mathrm{mol}$ are typically used in the melt blown and melt electrospinnig technologies [26] in order to reduce the processing pressure drop during the melt flow through capillaries having very small diameters $(0.025 \mathrm{~mm}-0.3 \mathrm{~mm}[26-27])$.

One may consider would wall slip occur in such high shear rate flow and if so what is its effect in the viscosity measurement/calculation in the presentation application? There are two mechanisms of slip - weak adhesive slip (due to desorption of molecules from the wall surface) and strong cohesive slip (caused by disentanglement of polymer chains in the bulk from a monolayer of polymer chains adsorbed on the wall) $[28,29]$. If the chains become fully disentangled at very high shear rates, only the occurrence of week adhesive slip would be applicable. Adhesive slip could appear if the drag force caused by the flow is higher than the binding force between the adsorbed chains and the wall surface. If 
adhesive slip would occur in the presented high shear rate measurements, one could expect decrease in the measured viscosities, i.e. decrease in the proportionality constant $K_{\infty}$. On the other hand, power-law exponent $n$ would remain the same considering constant slip intensity due to chosen, relatively narrow range of molar masses. It has been proved experimentally by Takahashi et al. [6] for PP at $230^{\circ} \mathrm{C}$ and at very high shear rates (i.e. for the same polymer type and comparable flow conditions utilized in our work) that there is no slip at the wall. In their experiment, they used two kinds of the capillaries with same $\mathrm{L} / \mathrm{R}$ ratio but different radii. From this one can deduce that the adsorption strength of PP chains to wall surface is high enough to suppress adhesive slip even if the shear rates are very high. Thus, utilization of a high surface energy metals for the flow channel manufacturing (i.e. materials with high work of adhesion for given polymer-wall interfaces) should be preferred to eliminate adhesive slip at very high shear rates to make the measured shear viscosity data reliable. At the end of this part, some experimental difficulties connected with high shear rate rheology of polymer samples with large differences in molar mass and branching (i.e. with higher viscosity and elasticity in comparison with the samples investigated in this work) are provided.

- Capillary die dimensions and experimental conditions have to be carefully chosen to ensure that the effect of viscous dissipation and pressure is mutually cancelled [11]. Increase in molar mass, i.e. in the shear viscosity, can leads to shear thickening at high shear rates because effect of pressure prevails over the effect of viscous dissipation [7] and the measured rheological data become unreliable.

- Increase of molar mass and branching increases melt relaxation time, which requires longer experimental times to reach pressure equilibrium during the measurements. This lowers the maximum attainable shear rate, at which the shear viscosity for given polymer can be reliably assessed due to limited size of the melt reservoir.

- Increase in the molar mass (i.e. in the shear viscosity) can leads to generation of very high pressure drops causing unwanted leakage flows or, in the worst case, barrel/die damage of utilized instrument. 
In summary, a high-shear rate secondary Newtonian plateau, $\eta_{\infty}$, was identified at three different temperatures for well entangled L-PP/LCB-PP blends above shear rates of $2 \cdot 10^{6} 1 / \mathrm{s}$ and its dependence on weight average molecular weight, $M_{w}$, was successfully related as $\eta_{\infty}(T)=K_{\infty}(T) \cdot M_{w}{ }^{n}$ with the exponent $\mathrm{n}=1.010$. The proportionality constant $K_{\infty}$ as well as the average value of high-shear rate flow activation energy was found to be lower for the blend in comparison with the pure L-PP with both values comparable with low-shear rate flow activation energy of PP like oligomer squalene. The parameter $n$ was found to be the same for both systems. This suggests that polymer chains are fully disentangled at very high shear rates and chain branching can enhance the flow in this regime due to smaller coil size and higher availability of the free volume (i.e. lower monomeric friction coefficient) in comparison with their linear counterparts.

\section{AUTHOR INFORMATION}

Corresponding Author*E-mail: mzatloukal@utb.cz

Notes: The authors declare no competing financial interest

\section{ACKNOWLEDGMENTS}

The authors wish to acknowledge Grant Agency of the Czech Republic (Grant registration No. 1605886S) for the financial support. The author also wishes to acknowledge Joachim Fiebig (Borealis Polyolefine) for donation of the polypropylene melt blown samples and help with the GPC measurements and analysis. 


\section{REFERENCES}

1. Ligon, S.C.; Liska, R.; Stampfl, J.; Gurr, M.; Mülhaupt, R. Polymers for 3D Printing and Customized Additive Manufacturing. Chem. Rev. 2017, 117, 15, 10212-10290.

2. Ding, Y.; Ro, H.W.; Alvine, K.J.; Okerberg, B.C.; Zhou, J.; Douglas, J.F.; Karim, A.; Soles, C.L. Nanoimprint Lithography and Role of Viscoelasticity in the Generation of Residual Stress in Model Polystyrene Patterns. Adv. Func. Mater. 2008, 18, 12, 1854-1862.

3. Rowland, H.D.; King, W.P.; Pethica, J.B.; Cross, G.L.W. Molecular Confinement Accelerates Deformation of Entangled Polymers During Squeeze Flow. Science. 2008, 322, 5902, 720-724.

4. Soles, C.L.; Ding, Y. Material Science: Nanoscale Polymer Processing. Science, 2008, 322, 5902, 689-690.

5. Ellison, C.J.; Phatak, A.; Giles, D.W.; Macosko, C.W.; Bates, F.S. Melt Blown Nanofibers: Fiber Diameter Distributions and Onset of Fiber Breakup. Polymer. 2007, 48, 11, 3306-3316.

6. Takahashi, H.; Matsuoka, T.; Kurauchi, T. Rheology of Polymer Melts in High Shear Rate. J. App. Pol. Sci. $1985,30,12,4669-4684$.

7. Kelly, A.L.; Gough, A.T.; Whiteside, B.R.; Coates, P.D. High Shear Strain Rate Rheometry of Polymer Melts. J. App. Pol. Sci. 2009, 114, 2, 864-873.

8. Haddout, A.; Villoutreix, G. Polymer Melt Rheology at High Shear Rates. Inter. Pol. Proc. 2000, 15, 3, 291296.

9. Benhadou, M.; Haddout, A.; Villoutreix, G. Injection of Polypropylene Reinforced with Short Glass Fibers: Rheological behavior. J. Reinf. Plast. And Comp. 2007, 26, 13, 1357-1366.

10. Rides, M.; Kelly, A.L.; Allen, C.R.G. An Investigation of High Rate Capillary Extrusion Rheometry of Thermoplastics. Pol. Test. 2011, 30, 8, 916-924.

11. Drabek, J.; Zatloukal, M.; Martyn, M. Effect of Molecular Weight on Secondary Newtonian Plateau at High Shear Rates for Linear Isotactic Melt Blown Polypropylenes. J. Non-New. Fl. Mech. 2018, 251, 107-118.

12. Drabek, J.; Zatloukal, M. Evaluation of Thermally Induced Degradation of Branched Polypropylene by Using Rheology and Different Constitutive Equations. Polymers. 2016, 8, 9, Art. Num. 317.

13. Ahirwal, D.; Filipe, S.; Neuhaus, I.; Busch, M.; Schlatter, G.; Wilhelm, M. Large Amplitude Oscillatory Shear and Uniaxial Extensional Rheology of Blends from Linear and Long-Chain Branched Polyethylene and Polypropylene. J. Rheo. 2014, 58, 3, 635-658. 
14. Maroufkhani, M.; Golshan Ebrahimi, N. Melt Rheology of Linear and Long-Chain Branched Polypropylene Blends. Iran. Pol. J. 2015, 24, 9, 715-724.

15. Wagner, M.H.; Kheirandish, S.; Stange, J.; Münstedt, H. Modeling Elongational Viscosity of Blends of Linear and Long-Chain Branched Polypropylenes. Rheol. Acta. 2006, 46, 2, 211-221.

16. Tabatabaei, S.H.; Carreau, P.J.; Ajji, A. Rheological and Thermal Properties of Blends of a Long-Chain Branched Polypropylene and Different linear polypropylenes. Chem. Eng. Sci. 2009, 64, 22, 4719-4731.

17. Stange, J.; Uhl, C.; Münstedt, H. Rheological Behavior of Blends from a Linear and a Long-Chain Branched Polypropylene. J. Rheo. 2005, 49, 5, 1059-1079.

18. Wang, Y. Application of Polymer Rheology in Melt Blowing Process and Online Rheological Sensor, Ph.D. Thesis University of Tennessee-Knoxville. 2004.

19. Raps, D.; Köppl, T.; Heymann, L.; Altstädt, V. Rheological Behavior of a High-Melt-Strength Polypropylene at Elevated Pressure and Gas Loading for Foaming Purposes. Rheo. Acta. 2017, 56, 2, 95111.

20. Schmidt, K.A.G.; Pagnutti, D.; Curran, M.D.; Singh, A.; Trusler, J.P.M.; Maitland, G.C., McBride-Wright, M. New Experimental Data and Reference Models for the Viscosity and Density of Squalane. J. Chem. And Eng. Data. 2015, 60, 1, 137-150.

21. Ferry, J.D.; In Viscoelastic Properties of Polymers, $3^{\text {rd }}$ ed.; John Wiley \& Sons: Chichester, 1980; p. 641.

22. Utracki, L.A.; Sedlacek, T. Free Volume Dependence of Polymer Viscosity. Rheol. Acta. 2007, 46, 4, 479494.

23. Bueche, F. Viscosity, Self-Diffusion, and Allied Effects in Solid Polymers. J. Chem. Phys. 1952, 20, 12, 1959-1964.

24. Dealy, J.M.; Larson, R.G.; In Structure and Rheology of Molten Polymers: From Structure to Flow Behavior and Back Again; Hanser Publishers: Munich, 2006; p. 516.

25. Münstedt, H.; Schwarzl, F.R.; In Deformation and Flow of Polymeric Materials; Springer-Verlag Berlin and Heidelberg, 2014; p. 573.

26. Nayak, R.; Polypropylene Nanofibers: Melt Electrospinning Versus Meltblowing; Springer: Cham, 2017.

27. Ward, G.F. Meltblown nanofibres for nonwoven filtration applications. Filtration and Separation 2001, 38(9), 42-43.

28. Hatzikiriakos, S.G. Wall Slip of Molten Polymers. Prog. In Pol. Sci. (Oxford). 2012, 37, 4, 624-643. 
29. Hatzikiriakos, S.G. Slip Mechanisms in Complex Fluid Flows. Soft Matter. 2015, 11, 40, 7851-7856. 